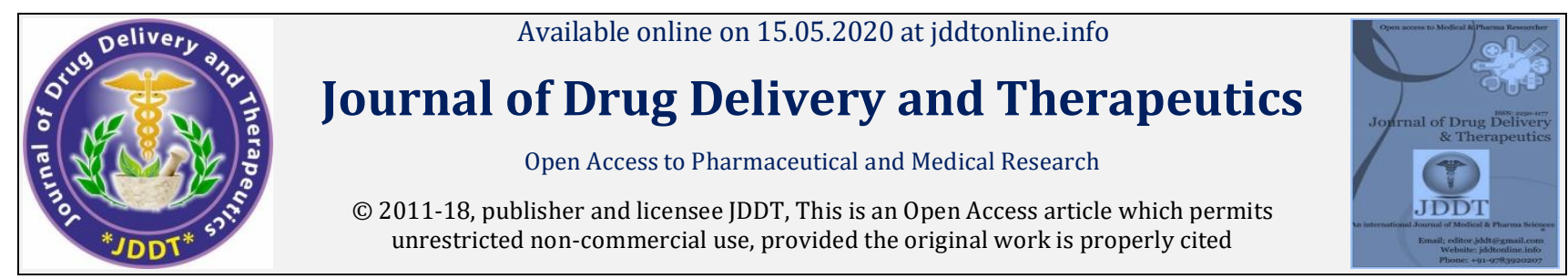

Open Access

Research Article

\title{
Development and Preclinical Testing of Nasal Aerosol for the Delivery of Novel Spray Dried Polyherbal Formulation to Treat Alzheimer's Disease
}

\author{
Rama Rao Nadendla*, Nagam Santhi Priya \\ Departmentof Pharmaceutics, Chalapathi Institute of pharmaceutical sciences, Lam, Guntur, Andhra Pradesh, India
}

\begin{abstract}
Alzheimer's disease (AD) is an irreversible, progressive brain disorder that slowly destroys memory and thinking skills and eventually the ability to carry out the simplest tasks. The present investigation was undertaken to evaluate anti-alzheimer's activity of novel herbal aerosol spray formulation containing pure extracts of Curcuma longa, Commiphora wightii and Withania somnifera.Pressurized aerosol packs containing polyherbal spray dried dispersions in the concentration range of $0.5,1$ and $2 \% \mathrm{w} / \mathrm{v}$ dispersed in 10/90, 20/80, 30/70/ 40/60, 50/50) propellant blends of HFA-134a were developed in 3 in 1 aerosol filling machine and evaluated. Behavioural studies were performed in male wistar rats and histopathological studies were performed. The preparations were also assessed for AChE inhibitory activity. Results with $\mathrm{P}$ values $<0.05$ were considered statistically significant. Chitosan exhibited compatibility with the polyherbal extracts in FT-IR studies. DSC thermogram revealed an endothermic peak of $65^{\circ} \mathrm{C}$ with chitosan. Spray dried poly herbal extracts exhibited a spherical morphology particle size distribution of 5-50 $\mu \mathrm{m}$ with a practical yield of 20-30\%. Aerosol formulations exhibited a particle size range below $10 \mu \mathrm{m}$. average weight per actuation of canister was $7-8 \mathrm{mg}$ with a total 210 deliveries per pack. Zeta potential of the formulations was \pm 0.997 . HPTLC fingerprinting showed band ranges at 256 and $366 \mathrm{~nm}$. The optimized aerosol spray in behavioral tests exhibited $10 \mathrm{mg} / \mathrm{kg}$ and $20 \mathrm{mg} / \mathrm{kg}$ intranasally reversed the scopolamine induced amnesia. Histopathological findings showed decreased Ach activity in male albino wistar rats. Percentage inhibition of formulation and standaed on AChE activity shoed an $\mathrm{IC}_{50}$ of $62 \%$ for $10 \mathrm{mg} / \mathrm{kg}$ aerosol spray and $72 \%$ with $20 \mathrm{mg} / \mathrm{kg}$ aerosol spray dosing.
\end{abstract}

Keywords: alzhiemer's disease; herbal; spray dried chitosan; aerosol; nasal spray;

Article Info: Received 19 March 2020; Review Completed 25 April 2020; Accepted 05 May 2020; Available online 15 May 2020

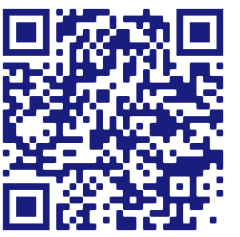

\section{Cite this article as:}

Nadendla RR, Santhi Priya N, Development and Preclinical Testing of Nasal Aerosol for the Delivery of Novel Spray Dried Polyherbal Formulation to Treat Alzheimer's Disease, Journal of Drug Delivery and Therapeutics. 2020; 10(3):185-194 http://dx.doi.org/10.22270/jddt.v10i3.4112

N. Santhi Priya, Assistant Professor, Chalapathi Institute of Pharmaceutical Sciences, Guntur Andhra Pradesh India

\section{INTRODUCTION}

Alzheimer's disease is a neurodegenerative disorder of uncertain cause and pathogenesis. It mostly affects the elderly. [1] In mild cases it results in forgetfulness and as the disease progresses it affects both short- and long-term memory. It is commonest cause of dementia in elderly, responsible for approximately $60-80 \%$ of cases. It has significant effect on quality of life. Currently available treatments can modulate the disease course and ameliorate some symptoms but no proven effective therapeutic cure for Alzheimer has been identified to date. Traditional medicinal system in India particularly Ayurveda mentions neuroprotective actions of plant drugs like Brahmi, Shankhapushpi, Amla, Guduchi, Tulsi, Ashwagandha and Haritaki, which can help in improving the treatment armamentarium for Alzheimer's disease.[2-3] The understanding of Alzheimer's disease neurobiology is improving now and the search for better treatment options is still on. This provides an opportunity for more research on integrated approach using existing therapies, traditional and alternative medicines with newer treatments and potential candidates for management of Alzheimer's disease. [9] Based on other existing evidence, it was depicted that oxidative stress has a considerably important role to play in this process. The hippocampal network, which is the main part of the brain has such a prominent role in long-term memory and spatial navigation, and it is also one of the strikingly first regions of the brain that can meticulously show damages, memory problems and disorientation in AD patients. Novel drug delivery systems has opened new areas for research in herbal drugs. In order to improve stability, studies are mostly dedicated to solid forms of polymeric systems. An interesting approach is spray drying technique. spray drying technique is widely used in pharmaceutical field since it allows the preparation of dry powders with specific characteristics such as particle size and shape. In addition, formulation process including encapsulation, complex formation and even polymerization can be accomplished in a single step. [8]. Use of natural 
biopolymers in drug delivery because of their biodegradability and biocompatibility is another choice for herbal drug encapsulation. Chitosan is a natural cationic polysaccharide of the linear co polymers which is suitable for medical applications. ${ }^{[7-8]}$ In this study, we pioneered the aerosol delivery of a spray dried microparticle formulation in a rodent model. The efficiency of different dosing techniques and formulations to target the brain were performed and compared.

\section{MATERIALS AND METHODS}

\section{Materials}

Curcumin, guggul and ashwagandha extracts were purchased from sun pure extracts (Hyderabad). All other chemicals were of analytical grade and procured from central stores, chalapathi institute of pharmaceutical sciences.

\section{Development of microparticles by spray drying technique:}

Spray-dried (SD) particles at different ratios were obtained by spray drying chitosan solutions of curcumin, guggul, ashwagandha under the conditions outlined in Table 1 . The feeding solution was prepared by dissolving each component in methanol to make a total concentration of $0.15 \% \mathrm{w} / \mathrm{v}$. The feed solution was passed through a stainless steel $0.7 \mathrm{~mm}$ diameter atomizing nozzle via a peristaltic feed pump at a flow rate of $15 \mathrm{~mL} /$ minute (pump rate $50 \%$ ). A set inlet temperature of $150^{\circ} \mathrm{C} \pm 2^{\circ} \mathrm{C}$ (primary drying step) resulted in outlet temperatures of $60^{\circ} \mathrm{C} \pm 3^{\circ} \mathrm{C}$. The atomization gas flow rate was $600 \mathrm{~L} / \mathrm{hour}$, and the aspiration rate was $35 \mathrm{~m} 3$ /hour (100\% aspirator). The resultant dry powder was blown through a highperformance cyclone separator and collected in the sample container. All SD powders were stored in glass vials sealed with parafilm in glass desiccators in the freezer at $-23^{\circ} \mathrm{C}$ under ambient pressure. [20] (TABLE1) (Fig 12)

\section{Development of pressurized aerosol:}

Pressurized packs containing chitosan polyherbal dispersions in the concentrations of $1 \%$ and $2 \%$ are solubilized in purified water and a fraction of tween 80 surfactant as stabilizer. These were mixed in 10/90, 20/80, $30 / 70,40 / 60$ and 50/50 propellant blends of HFA-134 filling and crimping procedures in 3 in 1 aerosol filling machine. Gross leakage of the aerosol packs were detected immediately after manufacture by immersion in water bath at $45^{\circ} \mathrm{C}$. the aerosol packs were further characterized for qualitative and quantitative tests. (Fig.13)

\section{Percentage yield:}

The weights of spray dried powders were collected. The yield was calculated by dividing these quantities by the total mass introduced in the preparation submitted to spray drying.

\section{Scanning electron microscopy for morphology and size analysis and zeta potential:}

The SEM pictures spray dried chitosan encapsulating herbal formulation by crosslinking were presented in Fig. 1. It can be seen that the spray dried chitosan microspheres were spherical with wrinkles on their surface. The spray drying parameters induced remarkable change in the surface morphology. Zeta sizer analysis report was presented in Fig 2. All the dynamic light scattering studies were performed at $25.0 \pm 0.1{ }^{\circ} \mathrm{C}$ at 20 seconds intervals for repeated measurements. For the zeta potential measurement, the $1 \mathrm{~mL}$ of diluted microparticle suspension was put in a universal folded capillary cell equipped with platinum electrodes. The electrophoresis mobility was measured and the zeta potential was calculated by the dispersion technology software provided in Malvern. (Fig.1, Fig.2 and Fig.3)

\section{Infra-red spectroscopy}

Infrared (FTIR) spectroscopy Fourier transform infrared spectrometry (FTIR) spectra of pure extracts (Sun pure extracts), spray dried formulations were recorded with a Varian, Inc., 7000e step-scan spectrometer (Agilent Technologies, Santa Clara, CA, USA). The spectra were collected with no further processing of the samples. The powder was placed on the sampling area, covered with a glass cover slip, and held in place with a specialized clamp. The spectra were scanned at an $8 \mathrm{~cm}-1$ spectral resolution from $700 \mathrm{~cm} 1$ to $4,000 \mathrm{~cm}-1$. The data were collected and analyzed using Varian Resolutions software (Agilent Technologies).

\section{Differential scanning calorimetry (DSC)}

Phase transition of pure extracts (as supplied by the manufacturer), SD formulations were studied by thermogram obtained using the TA Q200 DSC system (TA Instruments, New Castle, DE, USA) equipped with T-Zero® technology and an automated computer-controlled RSC-90 cooling accessory (TA Instruments). Approximately $3 \mathrm{mg}$ of powder was carefully weighed into hermetic anodized aluminum T-Zero® DSC pans (TA Instruments) and sealed with the T-Zero® hermetic sealer (TA Instruments). An empty, hermetically sealed, anodized aluminum pan was used as reference. DSC measurements were performed at the heating rate of $5.00^{\circ} \mathrm{C} /$ minute from $0^{\circ} \mathrm{C}$ to $350^{\circ} \mathrm{C}$. UHP nitrogen gas (Scott-Gross Company, Inc.), was used as the purging gas at a purge rate of $50 \mathrm{~mL} /$ minute. The glass transition temperature ( $\mathrm{Tg}$ ) was calculated using TA Universal Analysis (TA Instruments). (Fig.4 and Fig.5)

\section{Qualitative analysis of spray dried formulations:}

HPTLC analysis was carried out by taking $10 \mathrm{mg}$ of spray dried formulations. It was dissolved in $1 \mathrm{ml}$ methanol and centrifuged at $3000 \mathrm{rpm}$ for 5 minutes and used for HPTLC analysis as test sample. The aliquot of $2 \mu \mathrm{l}$ of the samples were loaded as $6 \mathrm{~mm}$ band length at a $15.0 \mathrm{~mm}$ application position in a $10 \times 10 \mathrm{~cm}$ silica gel $60 \mathrm{~F} 254 \mathrm{TLC}$ plate using a CAMAG automatic TLC sampler IV (CAMAG, Switzerland). Distance between the tracks was maintained at $23.3 \mathrm{~mm}$. The plates were prewashed with chloroform and dried in an oven at $60^{\circ} \mathrm{C}$ for 5 minutes. The samples loaded plates were kept in TLC Twin Trough Chamber $(20 \times 10 \mathrm{~cm})$ for saturation with the solvent vapours with respective mobile phase. The plates were developed in a linear ascending mode upto 84.9 mm. (TABLE 2] (Fig.14)

The mobile phase used is methanol. After the chromoplate development time of $20 \mathrm{~min}$, the plate was air-dried for 15 min to evaporate solvents. These plates were kept in photodocumentation chamber (CAMAG Automatic sampler 4) observed under white light, UV at 254 and $366 \mathrm{~nm}$ and the images were documented. Separated bands were observed in the remission-absorption mode at 254 and 366 nm operated by winCATS planar chromatography software manager. The plate size of $10.0 \times 10.0 \mathrm{~cm}$ at a sample application position between $15.0 \mathrm{~mm}$ to $84.9 \mathrm{~mm}$ with application volume of $2.0 \mu \mathrm{l}$ to $8.0 \mu \mathrm{l}$ was maintained to record the resolved bands. Derivitization of the plate was performed for clear resolution of bands. The plate was fixed and scanning was done at $366 \mathrm{~nm}$ by TLC Scanner 3 for the samples at full resolution. 
HPTLC profile of the spray dried samples was studied by using solvent system methanol, detected under UV 366, 254 $\mathrm{nm}$ and white light. The corresponding HPTLC images are presented in the results.

\section{Qualitative Evaluations of Aerosol Formulations}

Particle size distribution: Binocular Labomed vision 2000 TM microscope was used for particle size determination. Aerosol formulations under evaluation were sprayed on a glass slide. The slide was rinsed with $\mathrm{CCl}_{4}$ to prevent the excipients particles from interfering with the measurement of polyherbal drug particles. After sufficient rinsing with $\mathrm{CCl}_{4}$, the slide was placed under the microscope and particles were measured by using $100 \mathrm{X}$ magnification with oil immersion method. At least 100 particles in 25 different fields were measured. Results were reported as numbers of particles are less than or equal to $5 \mu \mathrm{m}$ and not more than 10 $\mu \mathrm{m}$.

Leakage rate test: Aerosol containers were weighed and inserted in water bath, maintained at $50^{\circ} \mathrm{C}$. After equilibration, containers were checked for presence of leaks in the form of air bubbles arising from orifice or valve crimp. These containers were wiped clean with a tissue paper and their weights were recorded $\left(\mathrm{W}_{1}\right)$. The containers were kept in upright position for 3 days and were weighed at the end of third day $\left(\mathrm{W}_{2}\right)$.

Leakage rate was calculated as:

Leakage rate: $365^{*} 24 / \mathrm{T}\left(\mathrm{W}_{1}-\mathrm{W}_{2}\right)$, Where $\mathrm{T}=$ Time in hrs.

\section{Quantitative Evaluations of Aerosol Formulations}

Average weight per actuation: Canisters were first detached from the adaptor body and their weights were determined. The first five sprays were fired in air and were referred to as "Test Firing". After the test fire, the canisters were thoroughly wiped with a tissue paper and their weights were recorded $\left(\mathrm{W}_{1}\right)$. Five successive deliveries were sprayed from the inhaler after placing the canisters back in their actuators. The canisters were subsequently removed from the adaptor and the valve stem and orifice were wiped clean. The containers were weighed again and their weights were recorded $\left(\mathrm{W}_{2}\right)$. (TABLE 8)

Average weight per actuation $=\left(\mathrm{W}_{1}-\mathrm{W}_{2}\right) / 5$

Evaluation of Anti-Alzheimer's activity:

\section{Experimental Animals:}

SD rats of either sex $(200-300 \mathrm{~g})$ were maintained for 7 days in the animal house of Chalapathi Institute of Pharmaceutical Sciences, Guntur under standard conditions temperature (24 $\pm 10^{\circ} \mathrm{C}$ ), relative humidity $(45-55 \%)$ and $12: 12$ light: dark cycle. The animals were fed with standard rat pellet and water ad libitum. The animals were allowed to acclimatize to laboratory conditions $48 \mathrm{~h}$ before the start of the experiment. 6 rats/group were used in all sets of experiments.

\section{Ethical Approval:}

All the protocols were approved by Institutional Animal Ethical Committee (IAEC) and conducted according to Committee for the Purpose of Control and Supervision of Experimental Animals (CPCSEA) registered no: 17/IAEC/CLPT/2018-2019 at Department of Pharmacology, Chalapathi Institute of Pharmaceutical Sciences, Guntur.

\section{Selection of Dose and Treatment Period:}

The learning and memory enhancing activity of the spray dried formulation was investigated using scopolamine- induced amnesia at a dose of $0.5 \mathrm{mg} / \mathrm{ml}$ in intra peritoneal route. The test animals were randomly chosen and divided into five groups having 6 rats in each as follows:

Group I: Normal control

Group II: (Inducing Group) scopolamine $0.5 \mathrm{mg} / \mathrm{kg}$ was administered i.p for 15 days).

Group III: (Standard Group) donepezil hydrochloride (2.5 $\mathrm{mg} / \mathrm{kg}$ was administered orally for 15 days)

Group IV: Formulation in low dose $(10 \mathrm{mg} / \mathrm{Kg})$ was administered through nasal route

Group V: Formulation in high dose $(20 \mathrm{mg} / \mathrm{Kg})$ was administered through nasal route

Diazepam $1 \mathrm{mg} / \mathrm{kg}$ was administered to rats and TL was noted after 45 min of injection on 8th day and after $24 \mathrm{hrs}$ Extracts and standard Donepezil hydrochloride were administered for successive 8 days. After $60 \mathrm{~min}$ of administration of the last dose on 8th day, Diazepam $1 \mathrm{mg} / \mathrm{kg}$ i.p was administered.

\section{Investigation of learning and memory activity in} Alzheimer's model by using 8-arm radial maze (8-arm) (Fig.7,8 and 10)

Behavioral Study:

Before starting the behavioral studies 1 week training was conducted. Only food and water was administered during this period.

\section{8 arm Radial Maze:}

The radial arm maze (RAM) has become an essential tool for testing memory in rats. The spatial memory was evaluated by the instrument. Open type radial arm maze was used in the study. It had a circular central arena and 8 equally sized arms $(20 \times 60 \mathrm{~cm})$. Small dishes with animal food was kept at far end inside each arm was mounted. Initially animals were habituated to the environment. (35) In the present study, baited and unbaited arms were fixed throughout the tests. The $1 \mathrm{st}, 3^{\text {rd }}, 5^{\text {th }}$, and $7^{\text {th }}$ arms were baited while the $2^{\text {nd }}, 4^{\text {th }}, 6^{\text {th }}$, and $8^{\text {th }}$ arms were unbaited. The rats was placed in the centre of the maze and allowed to freely explore the maze for 10 minutes on the first day. The rats were required to take the food pellets from each arm without making a re-entry into the arm already visited. The trail was terminated when the animal takes the food reward from all the eight arms or after 10 minutes if all the eight arms were not visited. Correct score was give when the visits an arm and collects the food reward and a maximum score of ' 8 ' can be attained per trail. The first entry into the baited arm was recorded as a correct choice. An entry into an unbaited arm was considered a reference memory error (RME). When a rat re-enters an already visited arm it was taken as a working memory error (WME).

Labrynth maze: This is a simple way to evaluate behavior in rodents such as learning ability, memory, and anxiety. The duration of time required for the animal to move from the starting point to the stopping point (Arrival Time) is recorded. If the animal takes significantly longer to arrive at the stopping point, this delay might be explained by external factors that lead to decreased cognition. The arrival time is determined by when the rat reaches the stop point and then stays there for at least $10 \mathrm{sec}$. (Fig 6 and 9)

Preparation of Intra nasal spray dried formulation: To100mg of spray dried formulation $2 \mathrm{ml}$ of tween 80 was added and dissolved. To this distilled water is added and make up the volume to $100 \mathrm{ml}(2 \%$ tween 80$)$ and fill this 
mixture in to inhalation container and operate the actuator for 2 seconds.

\section{Histopathological Studies:}

At the end of the study the rats were sacrificed on $22^{\text {nd }}$ day by using the method decapitation and whole brain was collected. Routinely, brain tissue is fixed in $10 \%$ formalin. The organs are isolated and samples were sent to Embiosis labs for interpretion of histopathological studies.

\section{Tissue preparation:}

Rats were deeply anesthetized with $3.5 \%$ chloral hydrate (35 mg/100 g, i.p.), and perfused by intracardiac infusion with phosphate buffer solution (0.1 M, pH 7.4) followed by $200 \mathrm{ml}$ of $4 \%$ paraformaldehyde fixative in phosphate buffer solution (0.1 M, pH 7.4) for $15 \mathrm{~min}$. Next, their brains were removed, isolated, postfixed in $4 \%$ paraformaldehyde ( $24 \mathrm{~h}$ ), and embedded in paraffin., the whole brain dissected out, blotted dry and immediately weighed and rinsed with ice-cold isotonic saline. Brain samples were then homogenized with 10 times (w/v) ice cold $0.1 \mathrm{M}$ phosphate buffer ( $\mathrm{pH}$ 7.4). Coronal sections $(10 \mu \mathrm{m}$ in thickness) were taken from the dorsal hippocampus and stained with haematoxylin and eosin. Finally, the numbers of intact neurons, in which one can vividly consider a distinctive nucleus, in the hippocampal C A1 pyramidal layer were counted using a light microscope (BX40, Olympus, New York, USA) connected to a camera (Olympus, DP12), and quantitatively analysed by Image J software.

\section{Estimation of In Vitro inhibition of Acetyl Cholinesterase Activity:}

Brain tissues were homogenized in 4 volumes of ice-cold Tris- $\mathrm{HCl}$ buffer (50 mmol/l, pH 7.4) Using a glass teflon homogenizer after cutting of brains into small pieces with a scissors (for $2 \mathrm{~min}$ at $5000 \mathrm{rpm}$ ). The homogenate was then centrifuged at $5000 \mathrm{rpm}$ for 6 mins to remove debris. Clear upper supernatant fluid was taken for estimation. Ellman's reagent, 5, 5'-dithio-bis-(2-nitrobenzoic acid), also known as DTNB, is a versatile water-soluble compound for quantitating free sulfhydryl groups in solution. DTNB reacts with a free sulfhydryl group to yield a mixed disulphide and 2-nitro-5thiobenzoic acid (NTB), a measurable yellowcolored product with molar extinction coefficient of 14.15 $\mathrm{mM}-1 \mathrm{~cm}-1$ at $412 \mathrm{~nm}$. DTNB is very useful as a sulfhydryl assay reagent because of its specificity for -SH groups at neutral $\mathrm{pH}$, high molar extinction coefficient and short reaction time. The enzyme inhibition (\%) was calculated from the rate of absorbance change with time $(\mathrm{V}=\mathrm{Abs} / \Delta \mathrm{t})$ the calculation as follows.

Inhibition $(\%)=100$ - Change of sample absorbance / Change of blank absorbance * 100

The experiment was done in triplicate and concentrations of the test extract that inhibit the hydrolysis of the substrate (acetylcholine) by 50\% (IC50) were determined by linear regression analysis between the inhibition percentage versus the extract concentration. (Fig.15)

\section{Statistical Analysis:}

The values are expressed as mean \pm SEM. The statistical analysis was performed using one way analysis of variance (ANOVA) followed by Dunnett's multiple comparison test. Comparisons were made between haloperidol group and test/standard groups. $P$ values $<0.05$ was considered statistically significant. The statistical analysis was done by using Graph pad prism version no: 6.0. (Fig 11)

\section{RESULTS AND DISCUSSION}

In the present research study, an attempt was made to use the spray dried herbal aerosol formulation in the treatment of alzheimer's disease. Spray drying of three herbal extracts dispersed in chitosan solution was performed. Differential scanning colorimetry studies showed good compatibility and stability of the herbal extracts with an endothermic peak of $65^{\circ} \mathrm{C}$ with chitosan during spray drying. HPTLC fingerprinting for qualitative analysis using CAMAG automatic TLC sampler 4 revealed a total of three bands in all tracks proving the presence of the herbal composition of Curcumin, Guggul and Ashawagandha in the spray dried formulations under UV 366, $254 \mathrm{~nm}$ and white light. Morphological parameters showed a particle size distribution between 5-45 $\mu \mathrm{m}$ and compatibility was assured from FT-IR. Spectra. The herbal compositions which are biocompatible were selected to play an important role in the long-term treatment of Alzheimer's disease with fewer side effects. Aerosol through nose to brain targeting will be a novel outlook in drug delivery and the scope of research can be extended. So in our current study the aerosol filling and sealing of spray dried dispersions was conducted n 3 in 1 aerosol filling and sealing machine. The aerosolization capacities were assessed in qualitative and quantitative tests. Average actuation revealed the total number of deliveries to empty the canister, leakage test revealed there is no loss of components. HFA 134a as propellant showed improved aerosolization of spray dried dispersions with improved particle size distribution. Blood brain barrier distribution and passage will be benefitted from dispersant tween 20. Behavioral studies were conducted. It was revealed that Scopolamine produces memory loss in brain cell of rats by increasing the GABAergic inhibitory facilitation and or by causing oxidative stress by releasing free radicals in the brain cavity. The damage by free radicals to brain tissue is associated with neurodegenerative disorders. The behavioral study results showed that no statistically significant differences were observed in brain AChE activity of formulation treated rats and control group rats. Ach is the most important neurotransmitter involved in the regulation of cognitive function. Scopolamine, a muscarinic antagonist readily crosses blood-brain barrier and blocks AChe receptors at synapse which impair memory and acquisition. On the other hand, administration of Haloperidol (1.4 mg kg-1, I.P.) significantly increased the brain AChE activity, which was reversed $(P<.05)$ by formulation administered intra nasally for 21 days. Donepezil (0.1 mg kg-1; i.p.) used as a standard drug, showed decrease in brain Ach activity of rats. It can also be explored from histopathological findings that brain organ weights

were increased in the formulations with low dose as well as high dose administration of the developed spray dried formulation. The spray dried formulation at a dose of $10 \mathrm{mg} / \mathrm{kg}$ and $20 \mathrm{mg} / \mathrm{kg}$ intra nasally reversed the scopolamine-induced amnesia in rats and produced memory enhancing activity. This was evident that by penetration of spray dried herbal formulations through nasal septum into the brain of rats and increase of herbal composition uptake through brain.

\section{ACKNOWLEDGEMENTS}

The authors are thankful to Sun pure Extracts Pvt., Ltd., Delhi, for providing the extracts as gift samples, Dr. K. Suresh Babu, Principal Scientist IICT, Hyderabad. We also extend our gratitude to management of Chalapathi Institute of Pharmaceutical Sciences for providing all the required facilities for the execution of the work. 


\section{Conflict of interest:}

None

\section{FUNDING STATEMENT}

The research work was supported by funding agency AICTERPS Scheme sanctioned with file no: 8-76/RIFD/RPS/Policy1-2016-2017

\section{REFERENCES:}

1. Small DH, McLean CA, "Alzheimer's disease and the amyloid $\beta$ protein",J Neurochem,1999; 73:443-49.

2. Prasad S, Gupta SC, Tyagi AK, Aggarwal BB, "Curcumin, a component of golden spice: From bedside to bench and back", Biotechnol Adv, 2014; 32(6):1053-64.

3. Knowles TP, Vendruscolo M, Dobson CM, "The amyloid state and its association with protein misfolding diseases", Nat Rev Mol Cell Biol, 2014; 15:384-96.

4. Santosh, T., "Formulation and Product Development of Nasal Spray: An Overview.", Scholars Journal of Applied Medical Sciences, 2016; 4(8D):2976-2985.
5. Kublik, H. and M. Vidgren "Nasal delivery systems and their effect on deposition and absorption. Advanced drug delivery reviews", 1998; 29(1):157-177.

6. Guo, C. and W.H. Doub, "The influence of actuation parameters on in vitro testing of nasal spray products. Journal of pharmaceutical sciences", 2006; 95(9):2029-2040.

7. Hebbar S, Dubey A, Ravi GS, Mascarenhas SB. "Studies on cross-linked chitosan hydrogel for matrix tablets of mountelukast sodium." Int J Appl Pharm, 2017; 9:22-9.

8. Anandharamakrishnan C, Ishwarya SP. Spray Drying Techniques for Food Ingredient Encapsulation. 1st ed. New Jersey: John Wiley and Sons, Ltd.; 2015 P 121-125

9. Sanka N, Santhipriya N, Nadendla RR. An updated review on Anti-Alzheimer's herbal drugs. Journal of Drug Delivery and Therapeutics 2018; 8(6):360-372

10. Nadendla RR, Lakshmi SS, SankaN, Santhi Priya N. Design and development of novel drug delivery system using herbal medicine to treat alzheimer's disease. Asian J Pharm Clin Res 2019; 12(4):202-210.

Table 1 Optimized polyherbal microparticles prepared by spray drying technique

\begin{tabular}{|l|l|l|}
\hline \multicolumn{3}{|l|}{ Qualitative tests on aerosol formulations } \\
\hline Formulations & Particle size distribution & Leak test \\
\hline F-1 & $100 \%$ particles are below $10 \mu$ & $0.01 \%$ \\
\hline F-2 & $100 \%$ particles are below $10 \mu$ & $0.07 \%$ \\
\hline F-3 & $100 \%$ particles are below $10 \mu$ & $0.40 \%$ \\
\hline
\end{tabular}

Table 2 Qualitative tests of aerosol formulations

\begin{tabular}{|l|l|}
\hline Parameters & Observations \\
\hline Appearance & Spherical \\
\hline Particle size & $5-50 \mu \mathrm{m}$ \\
\hline$\%$ yield & $20-30 \%$ \\
\hline
\end{tabular}

Table 3: \% inhibition of standard and Test formulations on AChE activity

\begin{tabular}{|c|c|c|c|c|}
\hline $\begin{array}{c}\text { Concentration } \\
(\mu \mathrm{g} / \mathrm{ml})\end{array}$ & $\begin{array}{c}\text { \% Inhibition of } \\
\text { Scopolamine } \\
(0.5 \mathrm{mg} / \mathrm{kg})\end{array}$ & $\begin{array}{c}\text { \% Inhibition of } \\
\text { Donepezil } \\
(2.5 \mathrm{mg} / \mathrm{kg})\end{array}$ & $\begin{array}{c}\text { \%Inhibition } \\
\text { by Test I } \\
(\text { Low dose })\end{array}$ & $\begin{array}{c}\text { \% Inhibition by } \\
\text { (High dose })\end{array}$ \\
\hline 25 & $5.400 \pm 0.410$ & $63.20 \pm 0.47$ & $29.51 \pm 0.95$ & $36.03 \pm 4.26$ \\
\hline 50 & $6.820 \pm 1.89$ & $69.74 \pm 1.82$ & $37.19 \pm 1.24$ & $44.62 \pm 4.45$ \\
\hline 100 & $13.42 \pm 0.95$ & $77.62 \pm 1.52$ & $43.70 \pm 1.53$ & $56.48 \pm 3.91$ \\
\hline 200 & $17.31 \pm 1.82$ & $89.76 \pm 1.57$ & $51.62 \pm 0.56$ & 63.221 .63 \\
\hline 400 & $23.16 \pm 2.95$ & $97.01 \pm 0.90$ & $62.37 \pm 1.56$ & $72.29 \pm 1.02$ \\
\hline
\end{tabular}

Table 4: Average weight per actuation of pressurized pack

\begin{tabular}{|c|c|c|}
\hline Formulation & Average weight per actuation & Number of deliveries \\
\hline Spray dried aerosol F-1 & 7.5 to $8 \mathrm{mg}$ & 210 \\
\hline
\end{tabular}




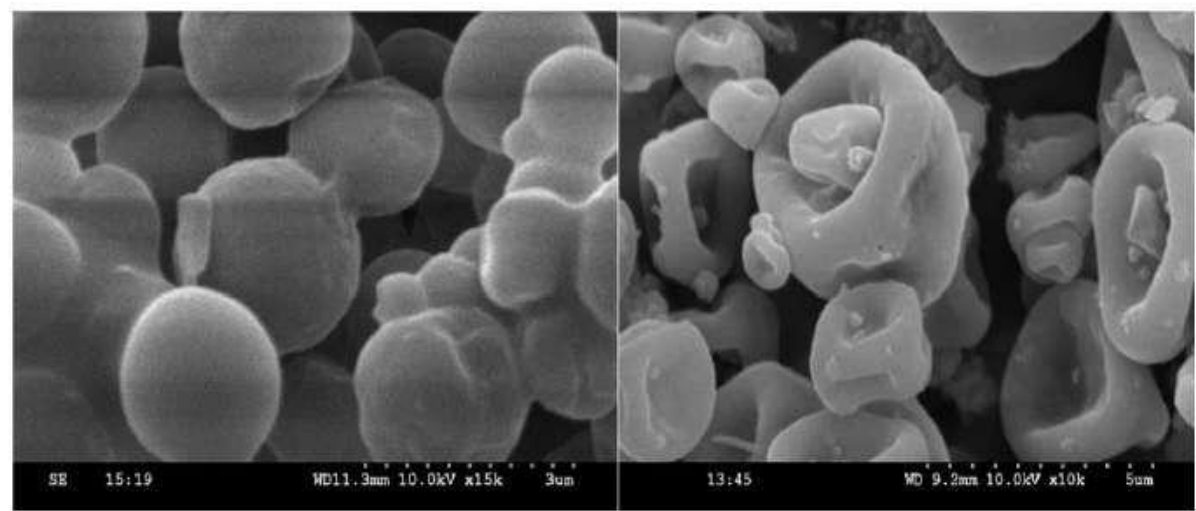

Fig.1 Scanning electron microscopy images of aerosol F-1

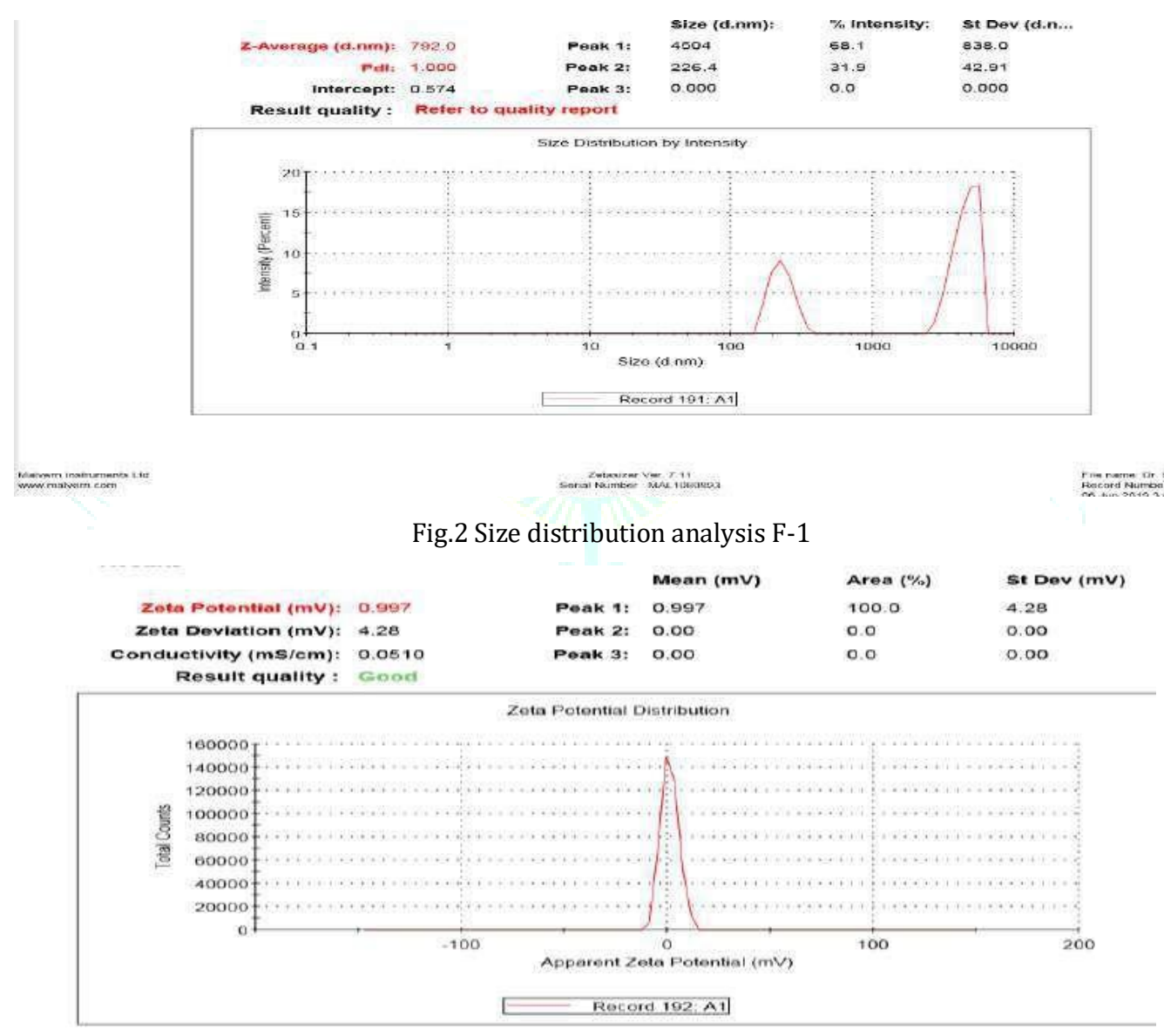

Fig.3 Zeta potential of aerosol formulation F-1

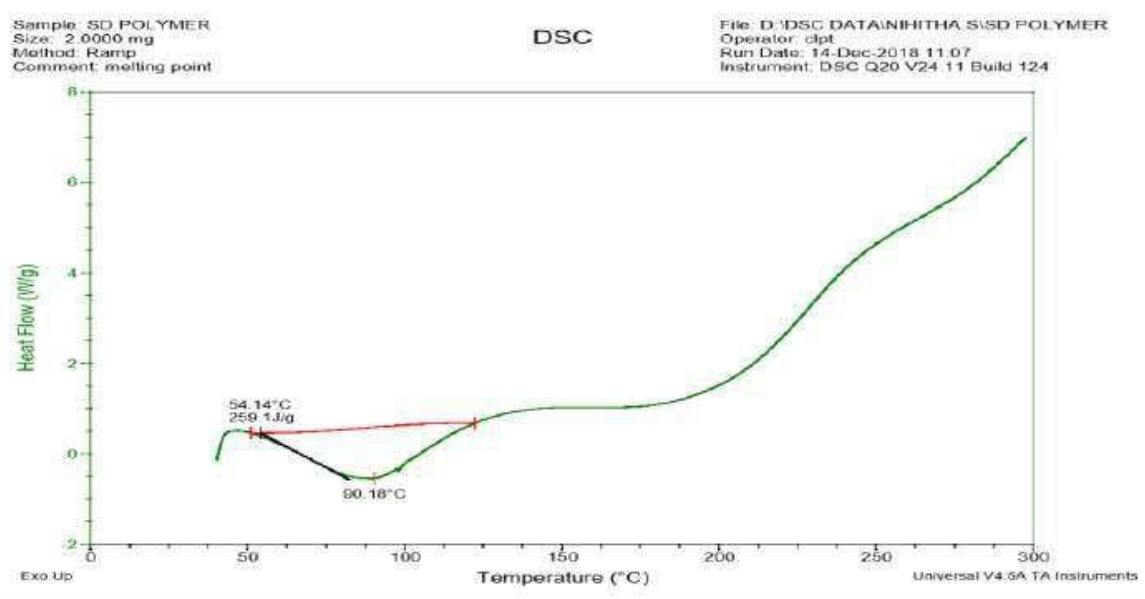

Fig.4 DSC report of spray dried Chitosan 


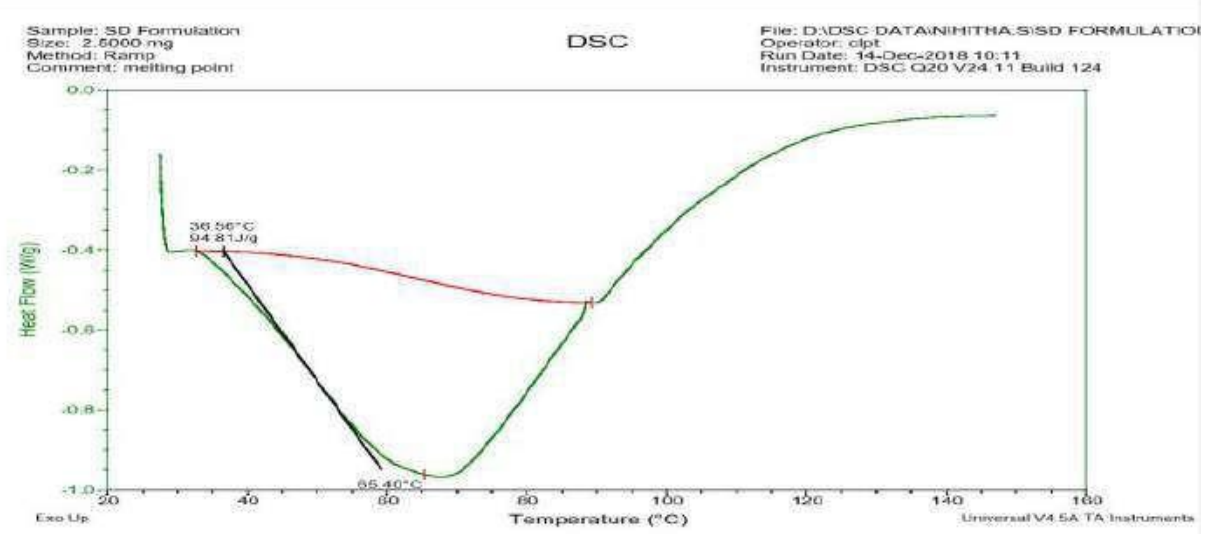

Fig.5 DSC Report of aerosol formulation F1

$$
\text { L a b ry } n \text {th } m \text { a z e }
$$

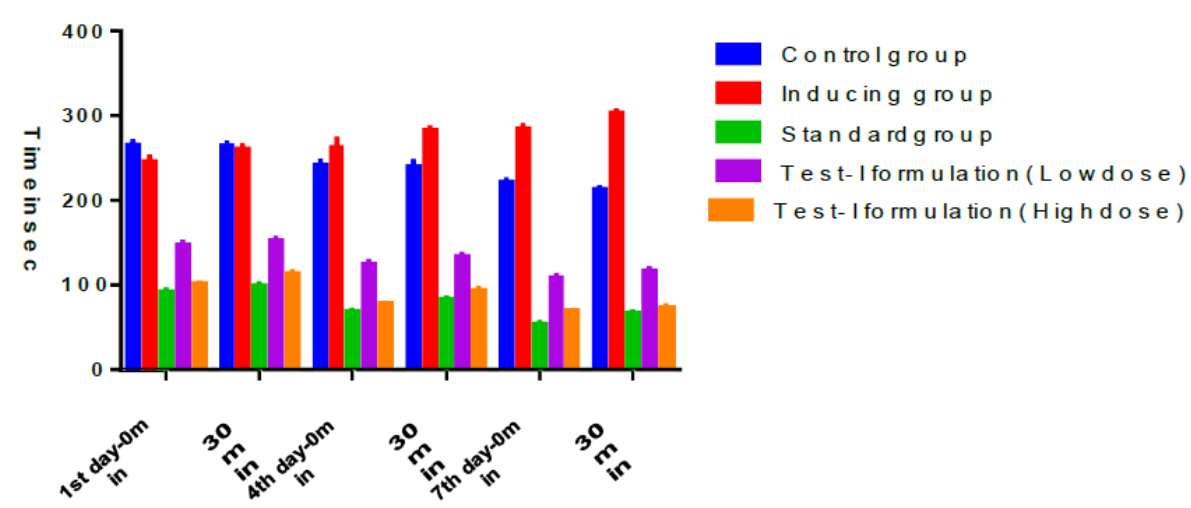

Fig.6 Comparision of behavioral study results in Labrynth maze

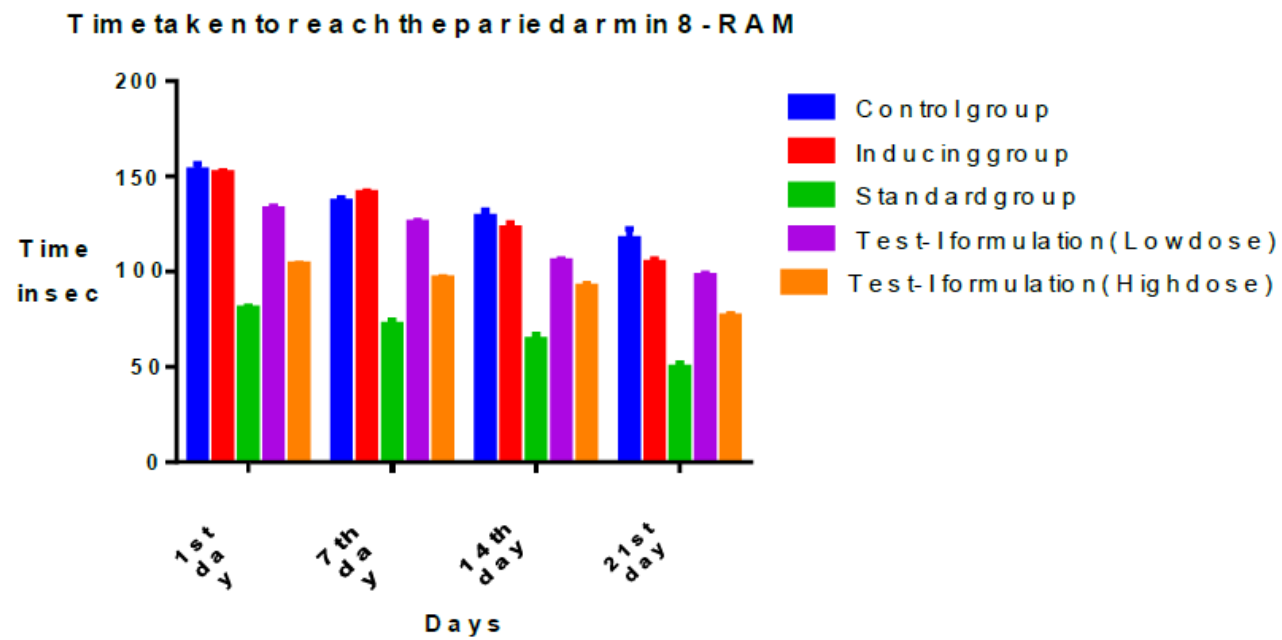

Fig.7 comparison of behavioral study results in 8 RAM maze 
$\mathrm{N}$ o. of e $\mathrm{n}$ trie $\mathrm{s}$ in B A a n d N B A in 8 - R A M

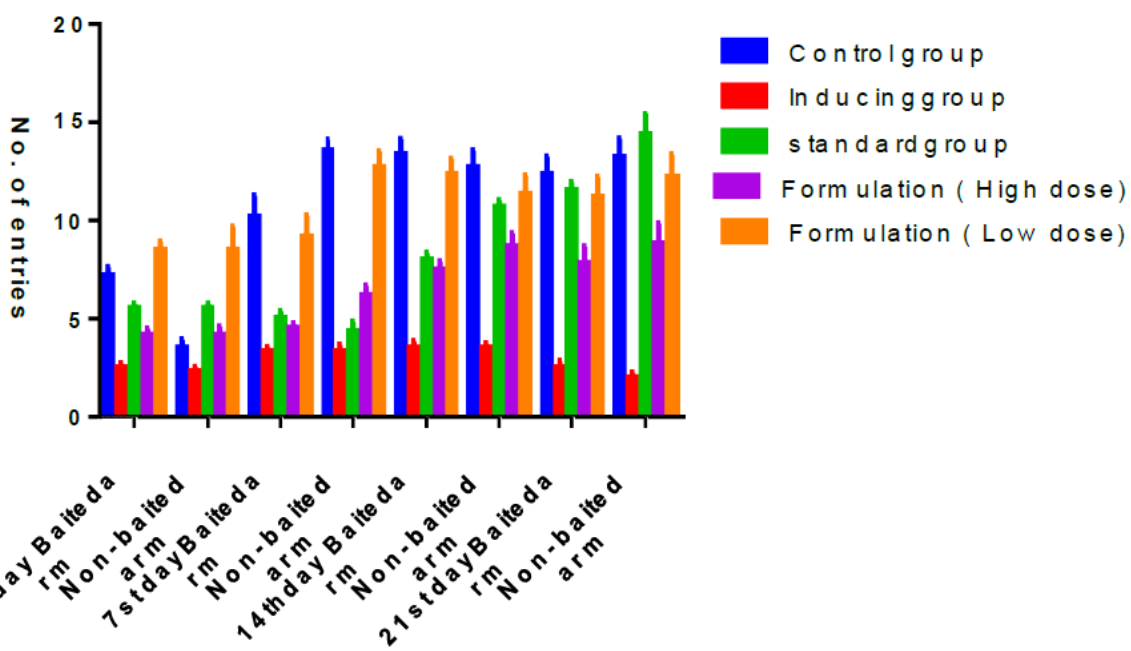

Fig.8 Comparision of behavioral study results in baited arm and non-baited arm in 8 RAM

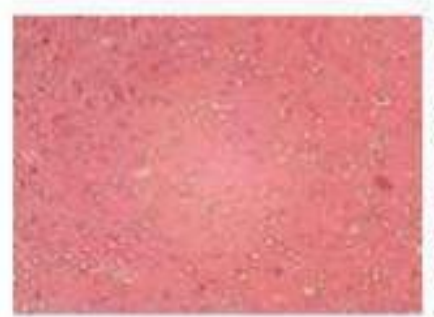

Normal control

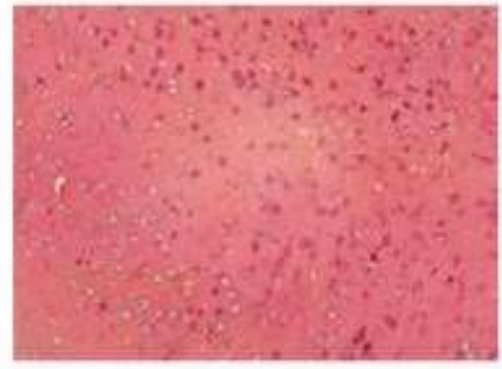

Formulation in low dose

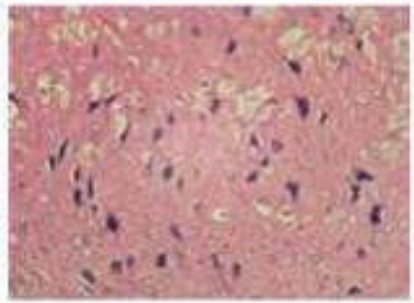

Induced group

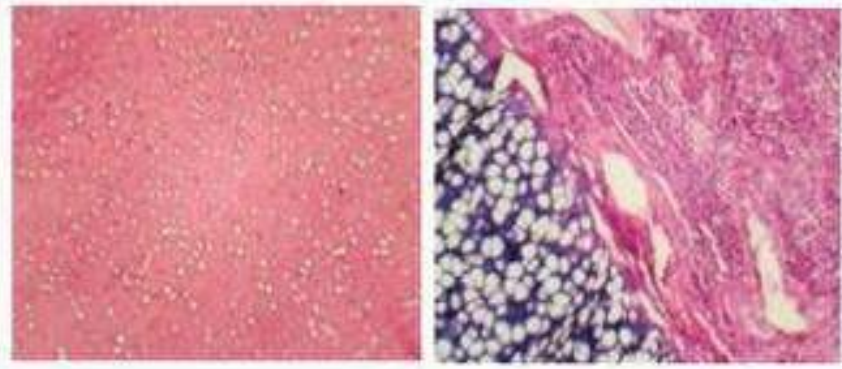

Formulation in high dose

\section{Nasal mucosa of Normal rat}

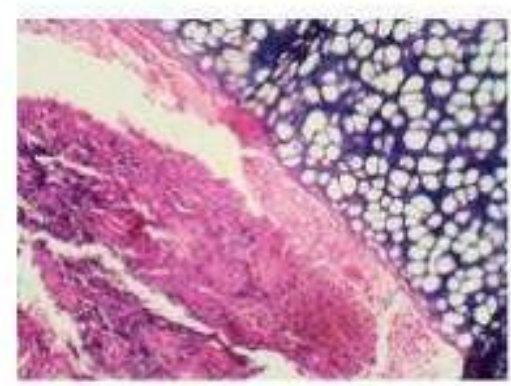

Nasal mucosa of rat after intranasal administration brain

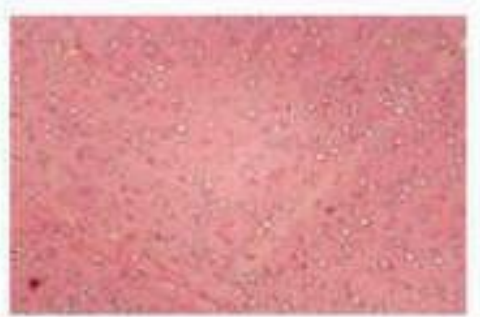

Standard group

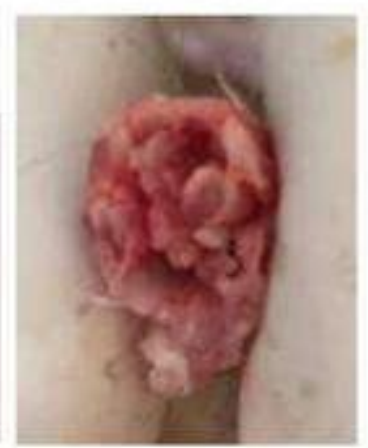

nasal septum

Fig.9 Histopathological findings - Labyrinth maze 


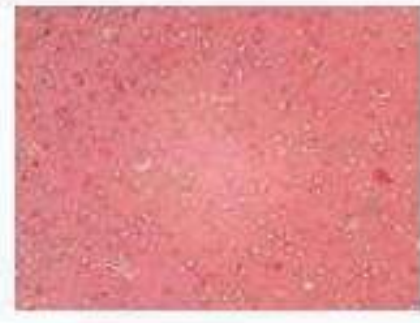

Normal control

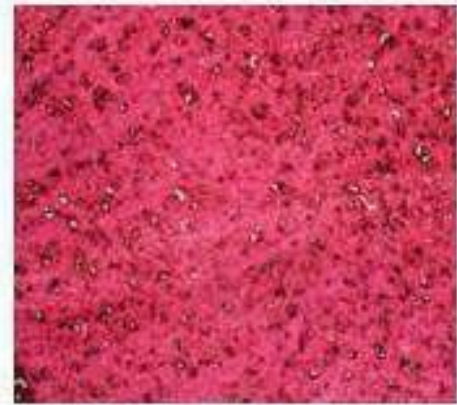

Formulation in low dose

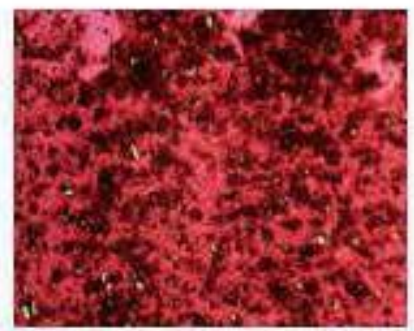

Inducing

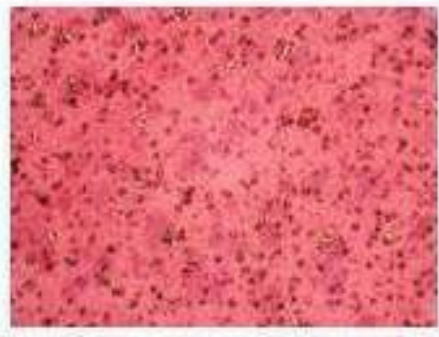

standard

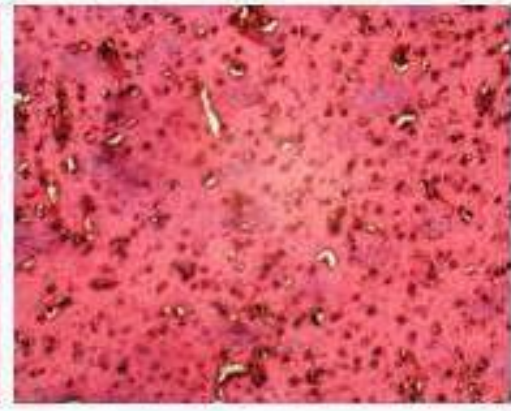

Formulation in high dose
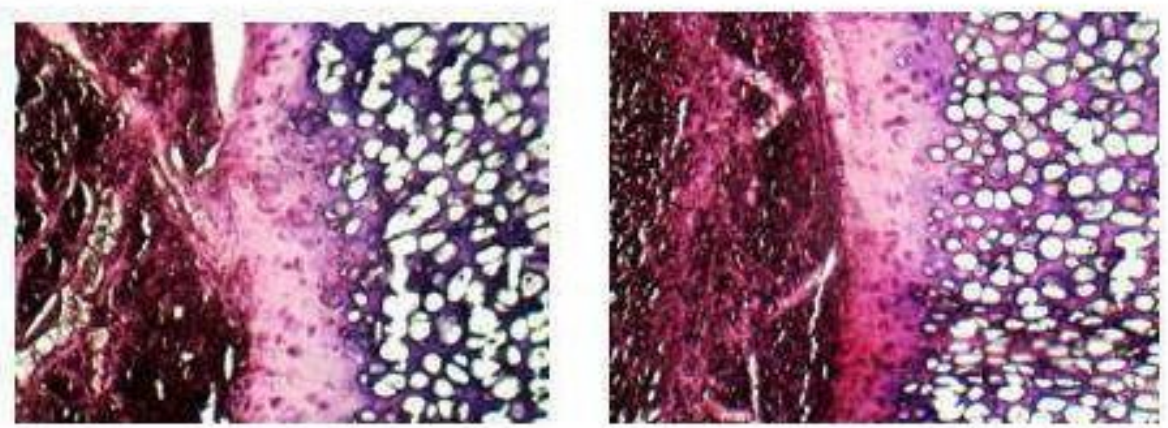

Nasal septum after intranasal administration of formulation after 21 days

Fig. 10 Histopathogical findings - 8 RAM reports

\begin{tabular}{l|l}
\hline Pvalue & 0.0457 \\
\hline Pvalue summary & * \\
\hline Statistically significant $(\mathrm{P}<0.05) ?$ & Yes \\
\hline Geisser-Greenhouse's epsilon & 0.5000 \\
\hline R square & 0.9949 \\
\hline
\end{tabular}

Fig.11 P -value in graph pad prism6 software 


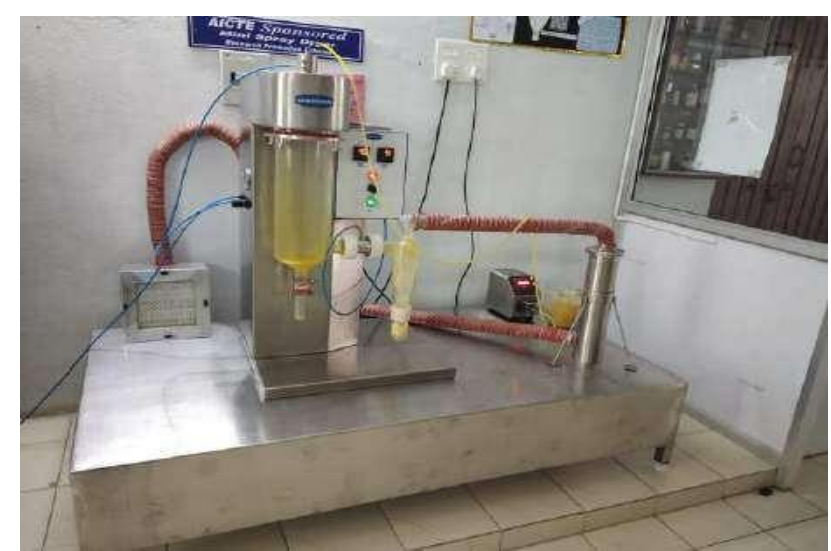

Fig.12 spray drying of herbal extracts
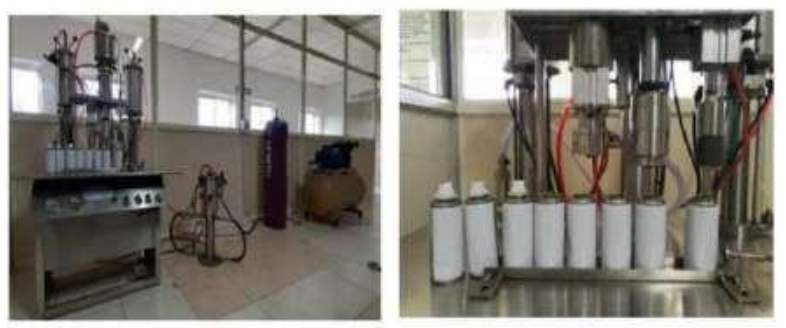

Fig.13 Aerosol filling in 3 in 1 aerosol filling and sealing machine
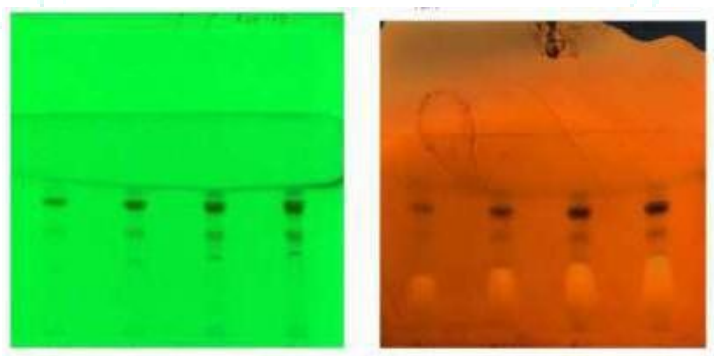

Fig.14 HPTLC chromatograms at 254 and $366 \mathrm{~nm}$

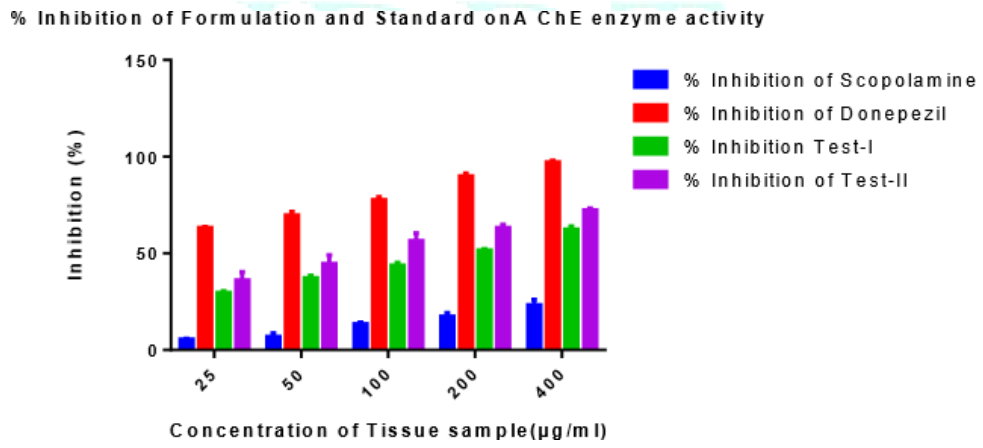

Fig.15 Percentage Inhibition of Standard and Test formulation on AChE Enzyme Activity 